\title{
EDUCATION
}

\section{Mentoring in Online Clinical Laboratory Science Courses}

\section{JANICE THOMAS, KRISTIN HADLEY}

\begin{abstract}
Online education, though proven to be as effective as traditional classroom instruction, can be a challenge, especially in a field that requires hands on experience, as does Clinical Laboratory Science (CLS). Contrary to most research, a CLS course in Introductory Hematology and Hemostasis taught at a public university in the western United States demonstrated slightly lower overall grades when taught online. Considering that CLS online students at this institution are required to achieve lab competency with the assistance of a field mentor or preceptor (as opposed to the simulated laboratory approach used on campus), it became beneficial to obtain feedback from CLS mentors who work with online students in various clinical sites. Mentor feedback was obtained by the administration of an online survey exploring three areas of mentorship: interpersonal, organizational, and cognitive.
\end{abstract}

Data collected demonstrated mentors' concerns with the interpersonal and cognitive aspects of their role. Mentors expressed the need for more communication with the department and university instructors regarding access to course objectives, schedules, and laboratory activity ideas in order to better assist students. Mentors exhibited a very positive response to the suggestion of an online resource for CLS mentors, suggesting the inclusion of an online forum or blog to communicate with instructors as well as other mentors in CLS.

This study may help other institutions of higher education seeking ways to improve CLS online programs. Understanding the mentor/mentee relationship and exploring mentors' perceptions of support suggested ways to offer assistance to clinical sites, hopefully leading to more meaningful clinical rotations for CLS online students.

ABBREVIATIONS: CLS-Clinical Laboratory Science, IHE-Institutions of Higher Education
INDEX TERMS: Education, Distance, Mentorship, Mentors, Preceptorship, Medical Laboratory Science, Inservice training

\section{Clin Lab Sci 2015;28(2):70}

Janice Thomas, MEd, MT (ASCP), Weber State University, Department of Medical Laboratory Sciences, Ogden, UT

Kristin Hadley, PhD, Weber State University, Teacher Education Department, Ogden, UT

Address for Correspondence: Janice Thomas, MEd, MT (ASCP), Weber State University, Department of Medical Laboratory Sciences, 3875 Stadium Way, Dept 3905, Ogden, UT 84405-3905, 801-626-8138, janicethomas@weber.edu

\section{INTRODUCTION}

Online education has become a viable option for students seeking an alternative to the traditional classroom. Students' positive response to online instruction indicates that this modality of teaching is well acknowledged, most likely due to the convenience and self-pacing approach it provides. ${ }^{1}$

Most research suggests that there is no significant difference in the academic achievement of students taking online courses compared to students taking traditional classroom courses. In fact, several studies point to online as the modality that leads to higher student achievement. ${ }^{2}$ However, despite the apparent success of web-based instruction, there are instances where this modality may not be as successful as teaching face-to-face. ${ }^{3,4}$

This was suggested in an introductory online course in Hematology and Hemostasis taught at a public university in the western United States. When compared to its online version the course demonstrated 


\section{EDUCATION}

a difference in overall course grades in favor of classroom instruction. CLS online courses in this institution are designed to offer the theory portion of the course online. The laboratory portion is completed concurrently with the assistance of an approved field mentor in the student's geographical area. Thus, the mentoring relationship plays a vital role in the success of the CLS online student, warranting further investigation of the role played by the CLS mentor.

\section{Mentorship Role in Online Education}

Field mentors play a crucial part in assisting online students to make the connection that comes from theory to application. ${ }^{5}$ While there is no universally accepted definition of mentoring roles, ${ }^{6}$ current literature associates mentoring with leading, motivating, training, supporting, supervising, modeling, and assessing individuals within a chosen discipline. ${ }^{7}$ In order to increase the chance of student success a field mentor should "act as a role model, facilitating learning and supervision that is appropriate to the student's area of practice" ${ }^{8}$ It is imperative that mentors maintain frequent contact with students, have a depth of understanding of the field, and possess passion for the work. ${ }^{9,10}$

Communication and clear expectations are of paramount importance in order for mentors to provide adequate assistance. While many online students are provided with handbooks from their accredited program that deliver mentorship information, the majority of students do not share this information with their mentors at the clinical site, leading to possible misunderstandings and unclear expectations. ${ }^{8}$ A field mentor needs to be aware of what is required to maintain an effective relationship with the student, and the student has to take initiative in learning as well. Both parties should be precise about the degree of autonomy expected in order for the student to achieve the learning outcomes. Setting ground rules and a schedule of learning and time requirements as part of a contract will allow for a successful mentor/mentee relationship. ${ }^{10}$

Unfortunately, not all mentors possess the necessary qualities or receive needed support to help students succeed in their field. A survey of nursing mentors demonstrated that many of them experienced difficulty with the cognitive aspects of the mentor role, needing further assistance in becoming familiar with the structure of students' theoretical studies, keeping up to date, providing structured feedback, and assessing students' knowledge and performance. ${ }^{11}$ Another study conducted within the field of nursing demonstrated the need for mentors to receive further support and contact from IHE in the form of reports regarding student progress as well as enhancing the documentation students bring with them to practice placements. ${ }^{5}$ To aid in this predicament, classroom assessment techniques may be modified to be used in a clinical setting, thus assisting mentors in providing experiences that will develop higher order thinking skills by using problem solving techniques and case study examples. ${ }^{12}$

\section{Mentoring CLS Online Students}

Most studies point to online education as the modality of choice when compared to traditional face-to-face instruction. ${ }^{2}$ Nevertheless there are instances when achievement is superior in students who are taught in a traditional classroom. An introductory course in Hematology and Hemostasis taught at a public university in the western U.S. demonstrated a small difference in overall course grades in favor of classroom instruction ( 3.6 compared to 3.1 on a 4.0 scale) when compared to the online version of the course. CLS online students enrolled in this institution are taught the same content as on-campus students. However, face-to-face students complete the laboratory portion on campus by means of a traditional simulated laboratory approach, while online students complete the laboratory portion in a clinical laboratory (often their place of employment) with the assistance of a field mentor. A field mentor is a CLS professional who is educated and has ample experience in the field. Often the field mentor is also the student's job supervisor.

Attributable to the fact that field mentorship is a significant difference between the online and oncampus programs, the role of the CLS mentor warranted investigation. This study aimed to examine opinions from mentors of students enrolled in Principles of Hematology and Hemostasis and Introduction to Laboratory Practices online. The purpose was to evaluate the challenges mentors face when working with CLS students, to assess their perceived level of support from the CLS department, and to solicit ideas and recommendations that would help the mentors fulfill their role more effectively. 


\section{MATERIALS AND METHODS}

In order to pinpoint possible reasons for the difference in overall course grades between online and face-to-face students, an evaluation of mentor perceptions was conducted as part of a larger study comparing online versus face-to-face instruction in CLS.

\section{Survey Instrument}

The survey instrument ${ }^{11}$ used to gather data was adapted from an instrument developed to investigate mentorship and online education in the nursing field and was used with permission. Wording adaptations were made to make it applicable to the CLS field. The instrument was distributed to 27 field mentors by email. Responses were tracked through an online survey tool. The survey was mostly quantitative in nature with responses using a four point Likert scale. In order to seek mentor recommendations a qualitative element was added by the researchers in the form of two open-ended questions: "My job as a mentor would be easier if ....", and "If your student's institution offered an online site for mentors, would you use it? How frequently? What would you want to see included in the site?"

In this survey, 24 questions were presented to the participants with two question stems. The first stem presented the question: "How often do each of the following factors cause you concern?" Respondents chose from a four point scale labeled as (1) Never a concern, (2) Occasionally a concern, (3) Frequently a concern, and (4) Always a concern. The second stem presented the question: "How easy do you find each of the following activities"? The four point scale used to answer this stem was (1) Extremely difficult, (2) Fairly difficult, (3) Fairly easy, and (4) Extremely easy. Questions within the survey assisted in gathering information pertaining mentorship challenges and perceived level of support. For both stems, the questions asked were related to organizational, interpersonal, and cognitive areas of mentorship. The questions were randomized and the categories were not made known to the respondents. It is pertinent to point out that the direction of the scoring ran differently for both stems. This reverse scoring is described by Moseley and Davies as a way to minimize routine answers by the respondents. ${ }^{11}$ Once gathered, the data were run through statistical analysis (IBM SPSS Statistics) where the scoring was reversed so all questions ranged from positive to negative. Thus, higher scores indicated negative responses. The questions and results within each mentorship category are summarized in Table 1 . In addition to the 24 questions, two open-ended questions were added by the researchers as a way to gather mentor recommendations and solicit ideas to help them fulfill their role more effectively (Table 2).

Table 1. Mentoring Challenges and Perceived Level of Support $\mathrm{n}=24$

\begin{tabular}{|c|c|c|c|}
\hline Questions & Mode & Mean & $\begin{array}{l}\text { Standard } \\
\text { Deviation }\end{array}$ \\
\hline \multicolumn{4}{|l|}{ Cognitive area } \\
\hline Mentor's own preparation & 2 & 1.67 & .702 \\
\hline Assessing students & 2 & 1.75 & .608 \\
\hline Creating a learning environment & 2 & 1.96 & .464 \\
\hline Providing feedback & 2 & 1.63 & .576 \\
\hline Determining competency & 2 & 1.75 & .608 \\
\hline Overall Cognitive Mode & 2 & & \\
\hline Cognitive Responses Total & & 8.75 & 2.048 \\
\hline Cognitive Responses Mean & & 1.75 & .4097 \\
\hline \multicolumn{4}{|l|}{ Interpersonal area } \\
\hline Student's gender & 1 & 1.04 & .204 \\
\hline Student's age & 1 & 1.00 & .000 \\
\hline Student's previous lab experience & 1 & 1.46 & .588 \\
\hline Attitudes of staff & 1 & 1.54 & .721 \\
\hline Mentor's personality & 1 & 1.29 & .690 \\
\hline Student's personality & 1 & 1.17 & .381 \\
\hline Student's preparation & 1 & 1.38 & .711 \\
\hline Relationship difficulty & 1 & 1.54 & .588 \\
\hline Integration to practice & 2 & 1.83 & .482 \\
\hline Acting as a role model & 2 & 1.83 & .482 \\
\hline Overall Interpersonal Mode & 2 & & \\
\hline Interpersonal Responses Total & & 14.08 & 2.733 \\
\hline Interpersonal Responses Mean & & 1.408 & .2733 \\
\hline \multicolumn{4}{|l|}{ Organizational area } \\
\hline Time of year & 1 & 1.21 & .415 \\
\hline Student's punctuality & 1 & 1.21 & .415 \\
\hline Extra work created by the student & 1 & 1.29 & .464 \\
\hline Number of shifts worked & 1 & 1.29 & .464 \\
\hline Staff skill & 1 & 1.46 & .721 \\
\hline Time availability & 2 & 1.71 & .464 \\
\hline Keeping up with student requirements & 2 & 2.08 & .504 \\
\hline Communicating with the instructor & 2 & 2.13 & .680 \\
\hline Knowing what is expected & 2 & 2.08 & .654 \\
\hline Overall Organizational Mode & 1 & & \\
\hline Organizational Responses Total & & 14.46 & 2.889 \\
\hline Organizational Responses Mean & & 1.61 & .321 \\
\hline
\end{tabular}

\section{Participants}

The university setting of this study was a large public university in the western United States. The on-campus student population is predominantly Caucasian and students typically live with their own families in surrounding suburban communities. Online students are sometimes from the local community but are more 
often from remote locations across the United States and occasionally throughout the world.

Table 2. Summary of Mentor Recommendations $n=22$

\begin{tabular}{ll}
\hline \multicolumn{1}{c}{ Question } & $\begin{array}{c}\text { Frequency } \\
\text { of Answers }\end{array}$ \\
Would you use an online website for mentors? & 14 \\
Yes & 1 \\
No & 7 \\
Maybe & 6 \\
How often? & 7 \\
Occasionally (less than once a week) & 1 \\
Often (at least once a week) & \\
Didn't specify & 4 \\
What should be included in the site? & 2 \\
Objectives/syllabus/timeline & 4 \\
Guidance and expectations & 3 \\
Blog with instructors and other mentors & 1 \\
Student requirements/assessment tips & \\
Lecture material & 2 \\
Mentoring job would be easier if... & \\
More communication with instructor & 7 \\
and other mentors & \\
Access to objectives, syllabus, and lab activity ideas & 7 \\
More time available &
\end{tabular}

Included in the study were field mentors of students enrolled in Introduction to Laboratory Practices and Introduction to Hematology and Hemostasis online.. A total of 24 mentors responded to the survey (89\%). Nine of them mentored Introduction to Clinical Laboratory Practices students, and 13 mentored Introduction to Hematology and Hemostasis students. Two mentor participants did not specify the course in which their student was enrolled. The high response rate was attributed to the use of the survey as part of a mid-semester mentor contact routinely performed by the instructors. While checking on the students' progress, instructors asked mentors to complete the survey as part of a course requirement. Students were also provided with a link and were asked to remind their mentors to fill out the survey.

\section{RESULTS}

\section{Mentoring Challenges and Perceived Level of Support}

A summary of questions and mentor responses to questions within the cognitive, interpersonal, and organizational areas is shown in Table 1. A mean of 1.75 and a mode of 2 in the cognitive category reiterate that CLS mentors found this area of mentorship to be the most challenging. Creating a learning environment was the most difficult aspect within the cognitive area of mentorship, followed by determining competency and assessing students. The mentor's own preparation was a problem for only one respondent.

Organizational and interpersonal issues were not of high concern for mentors. However, they did express occasional relationship difficulties and negative staff attitudes. They also expressed some concern with their own personality traits and students' prior preparation. The organizational category demonstrated a mean of 1.61 and a mode of 1 . Issues within this area included mentors' perceptions of support from the CLS department. Communicating with the instructor and having clear expectations were occasional concerns by mentors as was keeping up with the student program requirements.

\section{Mentor Recommendations}

Additional input from mentors was gathered through the administration of two open- ended questions that provided more information on what aspects they found difficult when working with CLS students, as well as suggestions on how their job as mentors could be made easier. This feedback provided opinions related to the development and implementation of an online support tool for CLS mentors.

Of the 22 mentor participants who responded to the open-ended question, 14 indicated they would use an online resource, stating they would log on at least once per week. The need for communication was expressed by a number of mentors, with four suggesting the inclusion of a blog or forum where mentors could communicate with not only class instructors, but also other mentors and "bounce ideas off each other" as stated by one respondent. Another participant expressed: "I feel disconnected with the instructor and not quite sure what I should be showing my student", while a different respondent conveyed the need to include "helpful hints to help students understand the most difficult aspects of CLS". The same respondent further added "there are times when the mentor understands something but has a hard time expressing the theory so the student gets it". Other mentors felt inadequate and unsure they were doing everything as they should, justifying their desire for more communication, course information, and clearer 


\section{EDUCATION}

expectations. More time availability and better laboratory resources were also specified by a number of mentors as ways to improve their job in assisting CLS students in the field.

\section{DISCUSSION}

Mentoring challenges expressed by the respondents were more prominent in the interpersonal and cognitive areas. Some of these results correlate with findings from Mosley and Davies ${ }^{11}$ when surveying nursing mentors. Mentors in Mosley and Davies' study experienced difficulty with the cognitive aspects of the mentoring role, needing further assistance in becoming familiar with the structure of students' theoretical studies, keeping up-to-date, providing structured feedback, and assessing students' knowledge and performance. ${ }^{11}$ Interestingly, providing adequate feedback was not among the most noted cognitive aspects of mentorship in the area of CLS as it was with nursing mentors. ${ }^{11}$

Integrating students to practice and acting as a role model were the two most prevalent concerns within the interpersonal area. Hodges ${ }^{8}$ found that acting as a role model is an imperative part of mentoring which facilitates learning. In the organizational capacity, mentors established that communicating with the instructors was a struggle, closely followed by knowing what was expected of them and keeping up with student requirements. These results concur with Pulsford et al. ${ }^{5}$ in the need for further support and contact from IHE in the form of feedback regarding student progress, as well as enhancing documentation. Interestingly, time availability was not as concerning for CLS mentors as it was for nursing mentors in Mosley and Davies study. ${ }^{11}$

On the whole, mentors desired to have more information regarding the course requirements and objectives. They also expressed the need for laboratory activity ideas they could use with their students. The suggestion of an online resource was positively accepted. It was also interesting to see that despite their experience in CLS, feelings of inadequacy were present among mentors when assisting students. They felt that even though they knew the material and procedures, struggles remained when trying to explain these in a manner that a student could understand.

It is important to remember that experienced laboratory professionals work in a very individualized environment, and collaborating with other individuals can be a challenge, especially when required to demonstrate procedures and assess their work. While the CLS department at the university states that mentors are not expected to be instructors ${ }^{13}$ the question remains: is it possible to mentor without instructing? In reality, CLS mentors are being asked to take part in lab instruction and assessment, which are areas for which most have not been formally trained. Consequently, feelings of inadequacy within their role are to be expected. For this reason, it becomes the responsibility of the CLS department to provide the necessary tools and resources that will allow mentors to feel comfortable in their responsibilities. Providing mentors with the necessary resources may not only help them feel more adequate cognitively but may even help with the interpersonal challenges of integrating students to practice and acting as a role model, as expressed by mentors in this study.

\section{Limitations of the Research}

A limitation of this study was the relatively small sample size of mentor participants. In addition, the researchers acknowledge that the information obtained in this study cannot be generalized and used to draw conclusions beyond the study's setting. However, it is hoped that the implications drawn from the results of this study will be used as a starting point to improve online education and field experiences for students who seek to pursue a CLS degree online.

\section{CONCLUSION}

Online education, though efficient and convenient, comes with an array of challenges, especially when implemented in a field that requires hands-on experience, as does CLS. Throughout this study, mentorship challenges in cognitive, interpersonal, and organizational areas were explored. Greater mentorship challenges were seen in the cognitive and interpersonal areas of mentorship. Field mentors perceptions of support from the university were expressed in the organizational area where mentors demonstrated the desire for more communication with the CLS department and clearer expectations. Mentor recommendations further reiterated the need for communication and access to course information and lab activity ideas. The suggestion of an online website for mentors was positively received. On the whole, results from this study suggested avenues to improve the 


\section{EDUCATION}

mentor/student relationship; thereby creating a learning environment that is better suited to the needs of mentors in the CLS field. Providing this type of support will not only help mentors feel better equipped in performing their duties but will also allow students who choose to pursue a CLS degree online to have more meaningful educational experiences while in their clinical rotations.

\section{REFERENCES}

1. Allen, E., Seaman, J. Staying the course. Online education in the United States, 2008. The Sloan Consortium [Internet]. 2008 Nov [cited 2009 Nov 29]. Available from http:// sloanconsortium.org/publications/survey/staying_course. Accessed 2013 September 16.

2. Shachar, M Neumann, Y. Differences between traditional and distance education academic performances: A meta-analytic approach. International Review of Research in Open and Distance Learning 2003;4(2):1-20.

3. Brown, B., Liedholm, C. Can web courses replace the classroom in principles of microeconomics? Am Econ Rev 2002;92(2):444-9.

4. Terry, N. Assessing instruction modes for master of business administration (MBA) courses. Journal of Education for Business 2007;82(4):220-5.

5. Pulsford, D, Boit, K, Owen, S. Are mentors ready to make a difference? Nurse Educ Today 2002;22(6):439-46.

6. Wunsch, M, ed. Mentoring revisited: Making an impact on individuals and institutions. San Francisco: Jossey-Bass; 1994

7. Morton-Cooper, A, Palmer, A. Mentoring, preceptorship, and clinical supervision. A guide to professional support roles in clinical practice. $2^{\text {nd }}$ ed. Oxford: Blackwell Science; 2000

8. Hodges, B. Factors that can influence mentorship relationships. Paediatr Nurs 2009;21(6):32-5.

9. Beck, S., Laudicina, R. Mentoring tomorrow's leaders in education. Clin Lab Sci 2001;14(1):38-44.

10. Ignash, J. Teaching and mentoring future leaders in the field. Community Coll Rev 2007;34(3):215-28.

11. Moseley, L. \& Davies, M. What do mentors find difficult? J Clin Nurs 2008;17(12):1627-34.

12. Davidson, J. Preceptor use of classroom assessment techniques to stimulate higher-order thinking in the Clinical Setting. The J Contin Educ Nurs 2009;40(3):139-43.

13. Weber State University [Internet] Lab Competency Requirements [Updated May 30, 2013; cited 2013 June 15]. Available from http://www.weber.edu/mls/degrees/online/ competencies.html. Accessed 2013 September 16. 